\title{
Anti-coccidial Activity of Moringa Oleifera Plant
}

\author{
El Banna H. A.*, M. Atef, Ghazal Nabil \\ Department of Pharmacology, Faculty of Veterinary Medicine, Cairo University, Giza, Egypt
}

Email address:

drelanna3@yahoo.cm (El Banna H. A.), atefshehata@live.com (M. Atef), gazal.nabil@yahoo (G. Nabil)

${ }^{*}$ Corresponding author

\section{To cite this article:}

El Banna H. A., M. Atef, Ghazal Nabil. Anti-coccidial Activity of Moringa Oleifera Plant. Animal and Veterinary Sciences. Vol. 4, No. 2, 2016, pp. 19-25. doi: 10.11648/j.avs.20160402.12

Received: February 12, 2016; Accepted: April 15, 2016; Published: May 4, 2016

\begin{abstract}
Moringa Oleifera leaves were screened for its toxicological effect and some pharmacological activities in broiler chicken. Toxicological effect was studied using upgrading oral doses of $75 \%$ ethanolic extract in different groups of mice with monitoring the toxicological symptoms and mortality rate. The anti-coccidal activity of Moringa Oleifera powdered leaves for prevention and its $75 \%$ ethanolic extract for treatment of coccidiosis were studied in broilers. The obtained result proved that there were no toxicological symptoms or mortalities obtained till oral administration of $6000 \mathrm{mg} / \mathrm{kg} \mathrm{b}$. wt. Inclusion of Moringa olifera powder $(0.5$ and $1 \%)$ to broiler's feed were very efficacious and equal to diclazuril (1ppm) in preventing symptoms of coccidiosis associated with experimental infection with mixed Eimeria species. The anti-coccidal activity of Moringa Oleifera powdered leaves and its $75 \%$ ethanolic extract were studied on one-day old chicks. The experimental infected chicks with mixed Eimeria species induced severe coccidiosis in non medicated chicks and led to high mortality reached to (26.76\%). Addition of 200 and 400ppm of Moringa Oleifera ethanolic extract induced marked curative effect of cocci diosis manifested by reduced mortality percent and improved PM lesion to be 13.3 and $10 \%$ respectively compared to $13.3 \%$ for group treated with the reference drug $(25 \mathrm{ppm})$ toltrazuril.
\end{abstract}

Keywords: Moringa Olifera-prophylactic and treatment - Coccidiosis

\section{Introduction}

Poultry plays very important role for mankind through food supply, income and employment generation, providing raw materials to some industries. The direct or indirect contribution of poultry industry is very dangerous. Coccidiosis is ubiquitous where chickens are reared (traditional, industrial or organic/bio farms). It is recognized as the parasitic disease that has the greatest economic impact on poultry industries worldwide [1]. Coccidiosis in poultry is still considered as one of the main diseases affecting performance of poultry reared under intensive production systems. Coccidiosis results in intestinal lesions, impaired growth, poor feed utilization, poor flock uniformity and increased mortality. Because it damages the intestinal lining, coccidiosis predisposes birds to the development of necrotic enteritis, another intestinal disease caused by the bacterium Clostridium perfringens.

The intensive use of anticoccidial drugs has led to the development of resistance [2]. Increasing development of drug-resistant coccidial species has stimulated searches for alternative control methods or new drugs. However, this has resulted in the increased cost of poultry products. Furthermore, drug or antibiotic residue in the poultry product is potentially offensive to the consumer. So the finding of natural replacer which improves the growth with prophylactic and curative effect against coccidiosis and without health hazard to human being is worthy.

The use of herbal remedies in the management of coccidiosis is not a new concept. For example, halofuginone, a quinazolinone alkaloid derived from Dichroa febrifuga, has been used as a coccidiostat, and the original extract from D. febrifuga, known as febrifugine, possesses antimalarial and anticoccidial activity [3]. The investigation of herbal materials as anticoccidial remedies therefore holds promise as an alternative in the control of coccidiosis. In addition to possibly lowering the cost of food production in different countries. Moringa Oleifera is one of the most 
important medicinal plants and it is the most widely cultivated species of family Moringaceae. Every part of Moringa is said to have beneficial properties that can serve humanity [4]. In addition, various parts of Moringa Oleifera contain minerals and area good source of protein, vitamins, $\beta$ carotene, amino acids and various phenolics. The Moringa plant provides a rich and rare combination of zeatin, quercetin, $\beta$ - sitosterol, caffeoylquinic acid and kaempferol. Various parts of this plant such as the leaves, roots, seed, bark, fruit, flowers and immature pods act as cardiac and circulatory stimulants, antioxidant, antibacterial, antimalarial and antifungal activities, and are being employed for the treatment of different ailments in the indigenous system of medicine, [5]. Furthermore, [6] reported the use of Moringa Oleifera acetone leaf extract on broiler chickens naturally infected with Eimeria species while [7], found that different parts of Moringa Oleifera were active against Leishmania donovani promastigotes and the flower extract of $\mathrm{M}$. oliefera was found to be the most potent antileishmanial agent when compared to other parts of the plant like leaf, root, bark and stem. Little studies have examined the anticoccidial efficacy of the plant in livestock; thus, this study has provided evidence for the efficacy of Moringa Oleifer and its curative and prophylactic anticoccidial activity. In addition its effect on body performance was also investigated

\section{Main Body}

\subsection{Plant Material}

The fresh Moringa Oleifera (Moringaceae) were collected during November to December, 2012 from private farm in El Sadat city. The plant specimen was authenticated by the Department of Botany, Faculty of Science, and Cairo University, Egypt.

\subsection{Plant Preparation}

The plant leaves were washed with tap water dried at room temperature then chopped into small fragments and pulverized by using grinder. Cold extraction was done with $75 \%$ ethanol for 72 hour at room temperature with intermittent shaking [8]. The extracts were concentrated in a rotatory evaporator at $50^{\circ} \mathrm{C}$ and refrigerated until use. The plant was used in its powdered form to determine its effect as prophylactic anti-coccidial activity. The plant was used in its ethanolic extract form for determining its curative anti-coccidial activity.

\subsection{Animals}

Mice: Mature mice weighing (20-25 grams) of both sexes were used for the toxicological study.

Chicks: One day old unsexed chicks weighing (45-55grams) were used for studying the effect on anti-coccidial activity. The birds were kept under good hygienic measures. Chicks were fed on balanced commercial ration and water offered ad libitum. The chicks were floor reared in separate units along the experimental periods.

Coccidia strains: Field strains of sporulated Eimeria oocysts were obtained from Department of Parasitology, Faculty of Veterinary Medicine, Cairo University. These strains include mixed Eimeria spp (Eimeria acervulina 19.5 x14.3 (4.5\%), Eimeria maxima $29 \times 23(29.5 \%)$, Eimeria necatrix 16.7 x14.2 (2.5\%), Eimeria tenella $22.9 \times 19.1(60 \%)$ and Eimeria brunetti $26.8 \times 21.7(3.5 \%)$.

\subsection{Drugs}

Diclazuril obtained from Pharma-Swede Egypt as feed additive $(0.2 \%)$ under trade name Diclomix ${ }^{\circledR}$.

Toultrazuril obtained from Pharma Swede Egypt as oral solution $(2.5 \%)$ under trade name Tolacox ${ }^{\circledR}$.

\section{Method}

\subsection{Toxicological Studies}

The toxicological pattern of the ethanolic extract of Moringa Oleifera leaves was studied by determination of LD50 in mice.

\subsection{Determination of LD50}

LD50 of the studied extract was carried out in mice according to method described by [9]. For these purpose five groups of 5 mice in each, weighing 20-25 grams one of them served as control group. Other four groups were dosed orally the studied extract on ascending doses $(30,60,90$, and $120 \mathrm{mg} / 20 \mathrm{~g} \mathrm{~b} . \mathrm{wt}$ ). Animals were put under observation for 24 hours for recording the toxic symptoms, mortality rate and post-mortem findings in each group. LD50 of the tested extract was calculated according to the following formula:

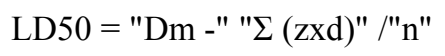

Where:

$\mathrm{Dm}=$ The largest dose which kill the animals. $\mathrm{z}=$ Mean of dead animals between 2 successive groups. $\mathrm{d}=$ The constant factor between 2 successive doses.

$\mathrm{n}=$ Number of animals in each group.

$\sum=$ The sum of $(\mathrm{a} \times \mathrm{b})$.

\subsection{Pharmacological Studies}

\subsubsection{Anticoccidial Effect}

Propagation and isolation of oocytes of mixed Eimeria spp: Isolation and propagation of the coccidia was carried according to Long [10] and the experimental design were carried out according to table1.

Preparation of Eimeria oocytes: The methods for these procedures are best followed from the description by $[11,12$, 13]. The calculated infective dose of culture (74000 oocytes $/ 1 \mathrm{ml}$ ) was given orally by insulin syringe which introduced intra-crop. 
Table 1. Experimental design for the anticoccidial activity.

\begin{tabular}{|c|c|c|}
\hline & Prophylactic capacity & Curative capacity \\
\hline Groups & $\begin{array}{l}\text { Standard (infected \& treated with standard drug). } \\
\text { - Control +ve (infected \& non- treated). } \\
\text { - Control - ve (non-infected \& non-treated). } \\
\text { Treated groups (Moringa Oleifera } 0.5 \& 1 \% \text { ). }\end{array}$ & $\begin{array}{l}\text { - Standard (infected \& treated with standard drug). } \\
\text { - Control +ve (infected\& non- treated). } \\
\text { - Control -ve (non- infected \& non-treated). } \\
\text { - Treated groups(Moringa Oleifera } 200 \& 400 \mathrm{mg} / \mathrm{liter} \text { ) }\end{array}$ \\
\hline Standard drug & Diclazuril 1ppm. & Toultrazuril 25ppm. \\
\hline Onset \& form of treatment & $\begin{array}{l}\text { Onset: From } 1^{\text {st }} \text { day on feed } \\
\text { Form: Powder. }\end{array}$ & $\begin{array}{l}\text { Onset: After appearance of clinical signs on drinking water } \\
\text { Form: Liquid. }\end{array}$ \\
\hline
\end{tabular}

\subsubsection{Post Mortem Examination}

It was carried out at 8 th for both experiments. Lesion scores were determined according to [14] Lesion score was 0 when no evident lesions were detected while a score was 4 when the lesions were extremely sever.

\subsubsection{Parasitological Examination (Oocyst Count)}

Fecal samples were collected from freshly evacuated faeces on the litter which spread on the ground for each group from 5 th to 11 th dpi. The oocysts count was carried out according to the method described by [15] using the McMaster counting chamber.

\subsubsection{Fecal Score}

A fecal score (1 to 5) was recorded for each group of birds from 5th to 11th day dpi. a score of 1 indicate normal faeces and a score of 5 indicate the presence of severe diarrhea and /or a profuse amount of blood.

\section{Result}

\subsection{Toxicological Studies}

LD50: Oral administration of the $75 \%$ ethanolic extract on ascending manner $30,60,90$, and $120 \mathrm{mg} / 20 \mathrm{~g}$ body weight showed no toxicological symptoms, mortalities and post-mortem changes. From this observation there is no LD50 recorded till oral administration of $6000 \mathrm{mg} / \mathrm{kg}$ body weight which corresponding to $15.5 \mathrm{~g}$ of air dried powdered leaves.

\subsection{Anticoccidial Effect}

\subsubsection{Prophylactic Efficacy}

Findings pertaining to survival percent, total oocyst count, lesion and fecal scores are presented in table (2). The experimental infected chicks with mixed Eimeria species induced severe coccidiosis in non-medicated chicks and led to high mortality reached to $(26.76 \%)$. Addition of 0.5 and $1 \%$ of Moringa Oleifera powdered leaves reduced mortality to be 6.7 and $4.3 \%$ respectively. Inclusion of Moringa Oleifera powder $(0.5$ and $1 \%)$ to broiler's feed were very efficacious and equal to feed additive in preventing symptoms of coccidiosis associated with experimental infection with mixed Eimeria species and decreased significantly the total oocyst count and lesion score.

The effect of Moringa Oleifera as feed supplement on performance of control and coccidia infected chicken was presented in tables $(3,4 \& 5)$. Use of Moringa Oleifera leaves powder in concentration of 0.5 and $1 \%$ induced an improvement in body weight with enhancement of the cumulative FCR in both control healthy and coccidia infected broilers.

Table 2. Anticoccidial prophylactic capacity of Moringa Oleifera in experimentally Eimeria-infected broiler chickens ( $n=15)$.

\begin{tabular}{|c|c|c|c|c|c|c|}
\hline Group No. & \multicolumn{2}{|c|}{ Used concentration } & Survival (\%) & Total oocyst $\mathrm{No}\left(\mathrm{x} 10^{3} / \mathrm{g}\right)$ & Lesion score & Fecal score \\
\hline \multirow{2}{*}{ Control groups } & \multirow{2}{*}{\multicolumn{2}{|c|}{$\begin{array}{l}\text { Control non- treated } \\
\text { Control non-infected non-treated }\end{array}$}} & 73.33 & $629.75 \pm 23.47^{\mathrm{a}}$ & $3.57 \pm 0.51^{\mathrm{a}}$ & $4.8 \pm 0.42^{\mathrm{a}}$ \\
\hline & & & 100.0 & $0.0 \pm 0.0^{\mathrm{d}}$ & $0.0 \pm 0.0^{\mathrm{d}}$ & $1.0 \pm 0.0^{\mathrm{b}}$ \\
\hline \multirow{3}{*}{ Treatment } & Diclazuril & $1 \mathrm{ppm}$ & 96.7 & $36.7 \pm 5.62^{c}$ & $0.37 \pm 0.042^{b}$ & $1.3 \pm 0.1$ \\
\hline & Moringa & $0.5 \%$ & 93.3 & $67.8 \pm 4.52^{b}$ & $0.72 \pm 0.022^{\mathrm{bc}}$ & $1.5 \pm 0.23^{b}$ \\
\hline & Oleifera & $1 \%$ & 96.7 & $44.4 \pm 3.38^{\mathrm{c}}$ & $0.40 \pm 0.11^{\mathrm{bc}}$ & $1.4 \pm 0.21^{\mathrm{b}}$ \\
\hline
\end{tabular}

Values with different letters $(\mathrm{a}, \mathrm{b}, \mathrm{c}, \mathrm{d})$ within the same column are significantly different at $\mathrm{P}$ value $\leq 0.05$

Table 3. The effect of Moringa Oleifera as feed additive on performance of control healthy broiler chicken ( $n=15)$.

\begin{tabular}{llll}
\hline Group & & Final body weight g & Feed consumption g \\
\hline Control non treated & & 1850 & 3348.5 \\
Diclazuril & $1 \mathrm{ppm}$ & 1900 & 3002 \\
& $0.5 \%$ & 1950 & 3178 \\
M. Oleifera powder & $1 \%$ & 2100 & 3130 \\
\hline
\end{tabular}


Table 4. The effect of Moringa Oleifera as feed additive on performance of coccidia infected chicken.

\begin{tabular}{lllll}
\hline Group & & Final body weight $\mathbf{g}$ & Feed consumption $\mathbf{g}$ & FCR \\
\hline Infected non treated & & 1490 & 3085 & 2.1 \\
Diclazuril & $1 \mathrm{ppm}$ & 1885 & 3092 & 1.64 \\
M. Oleifera powder & $0.5 \%$ & 1818 & 2910 & 1.60 \\
& $1 \%$ & 1850 & 2870 & 1.55 \\
\hline
\end{tabular}

Table 5. Gross P. M and histopathological examination at $8^{\text {th }}$ day of age of the anticoccidial prophylactic capacity.

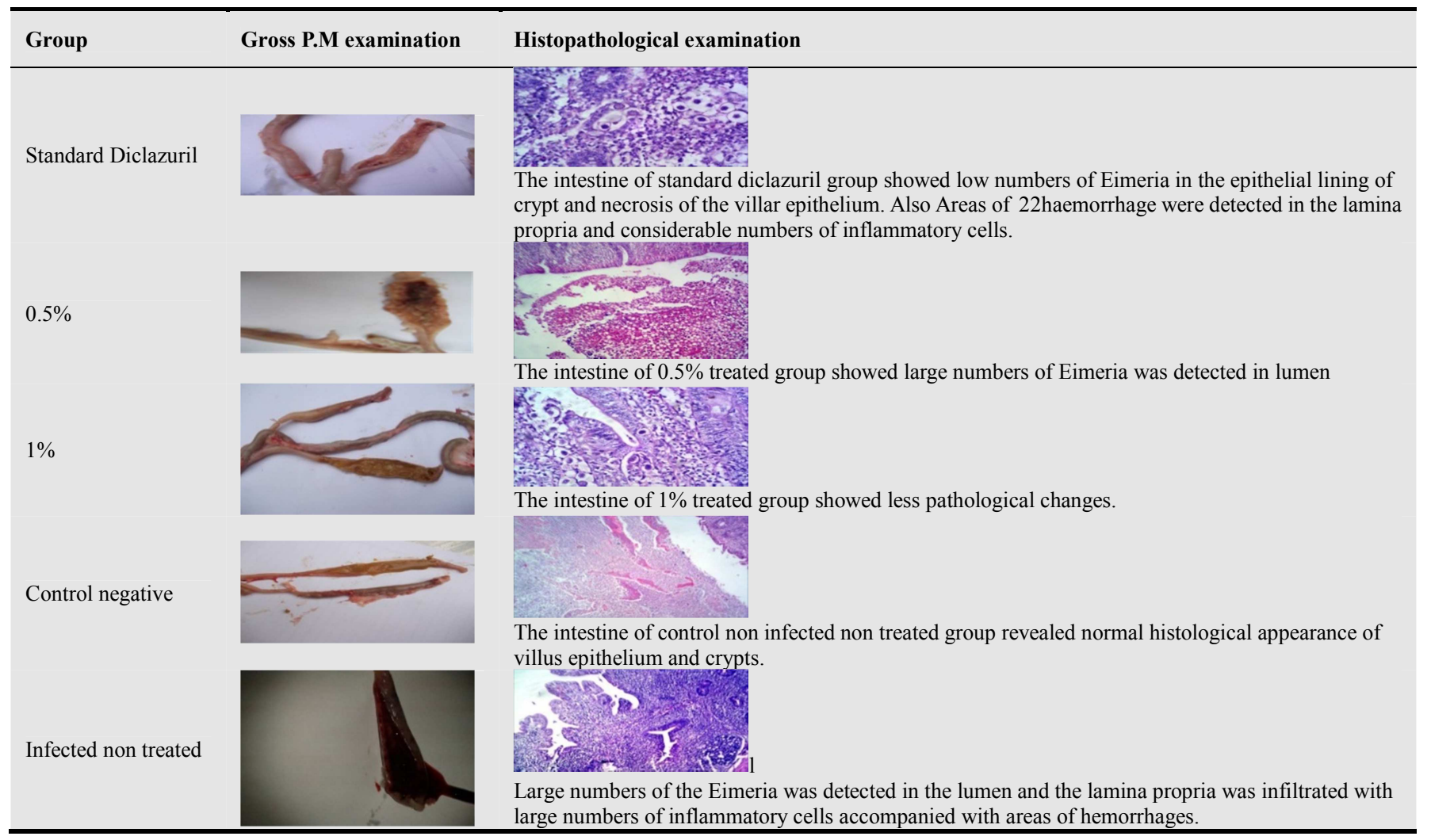

\subsubsection{Curative Efficacy}

Findings pertaining to mortality percent, total oocyst count, lesion and fecal scores, are recorded in table (6\&7). The experimental infected chicks with mixed Eimeria species induced severe coccidiosis in non -medicated chicks and led to high mortality reached to (26.76\%). Addition of 200 and 400ppm of Moringa Oleifera ethanolic extract reduced mortality to be 13.3 and $10 \%$ respectively compared to $13.3 \%$ for group treated with the reference drug ( $25 \mathrm{ppm}$ toltrazuril) and decreased significantly the total oocyst count and lesion score.

Table 6. Anticoccidial curative capacity of Moringa Oleifera ethanolic extract in experimentally Eimeria infected-broiler chicken.

\begin{tabular}{|c|c|c|c|c|c|c|}
\hline \multirow{2}{*}{ Used concentration } & \multirow{2}{*}{\multicolumn{2}{|c|}{ Survival (\%) }} & \multicolumn{2}{|l|}{ Total oocyst No (x $\left.10^{3} / \mathrm{g}\right)$} & \multirow{2}{*}{ Lesion score } & \multirow{2}{*}{ Fecal score } \\
\hline & & & During two days before treatment & During 5 days post treatment & & \\
\hline Control infected non-treated & 73.33 & & $7.5 \pm 0.61^{\mathrm{a}}$ & $6.21 .8 \pm 17.38^{\mathrm{a}}$ & $3.57 \pm 0.51^{\mathrm{a}}$ & $4.8 \pm 0.42^{\mathrm{a}}$ \\
\hline Control non-infected non-treated & 100.0 & & $0.0 \pm 0.0^{\mathrm{b}}$ & $0.0 \pm 0.0^{\mathrm{d}}$ & $0.0 \pm 0.0^{\mathrm{d}}$ & $1.0 \pm 0.0^{\mathrm{d}}$ \\
\hline Toltrazuril & $25 \mathrm{ppm}$ & 86.67 & $8.7 \pm 1.27^{\mathrm{a}}$ & $256.75 \pm 21.43^{\mathrm{b}}$ & $0.97 \pm 0.067^{\mathrm{c}}$ & $1.4 \pm 0.23$ \\
\hline \multirow{2}{*}{ Moringa Oleifera } & $200 \mathrm{ppm}$ & 86.67 & $7.4 \pm 0.59^{\mathrm{a}}$ & $285.2 \pm 9.45^{\mathrm{b}}$ & $1.1 \pm 0.12^{\mathrm{b}}$ & $1.9 \pm 0.44 b^{c}$ \\
\hline & $400 \mathrm{ppm}$ & 90.0 & $7.9 \pm 0.81^{\mathrm{a}}$ & $146.6 \pm 8.57^{\mathrm{c}}$ & $0.81 \pm 0.14^{\mathrm{c}}$ & $1.5 \pm 0.31 b^{c}$ \\
\hline
\end{tabular}

Values with different letters (a, b, c, d) within the same column are significantly different at $\mathrm{P}$ value $\leq 0.05$ 
Table 7. Gross P.M and histopathological examination at $8^{\text {th }}$ day of age of the anticoccidial curative capacity.

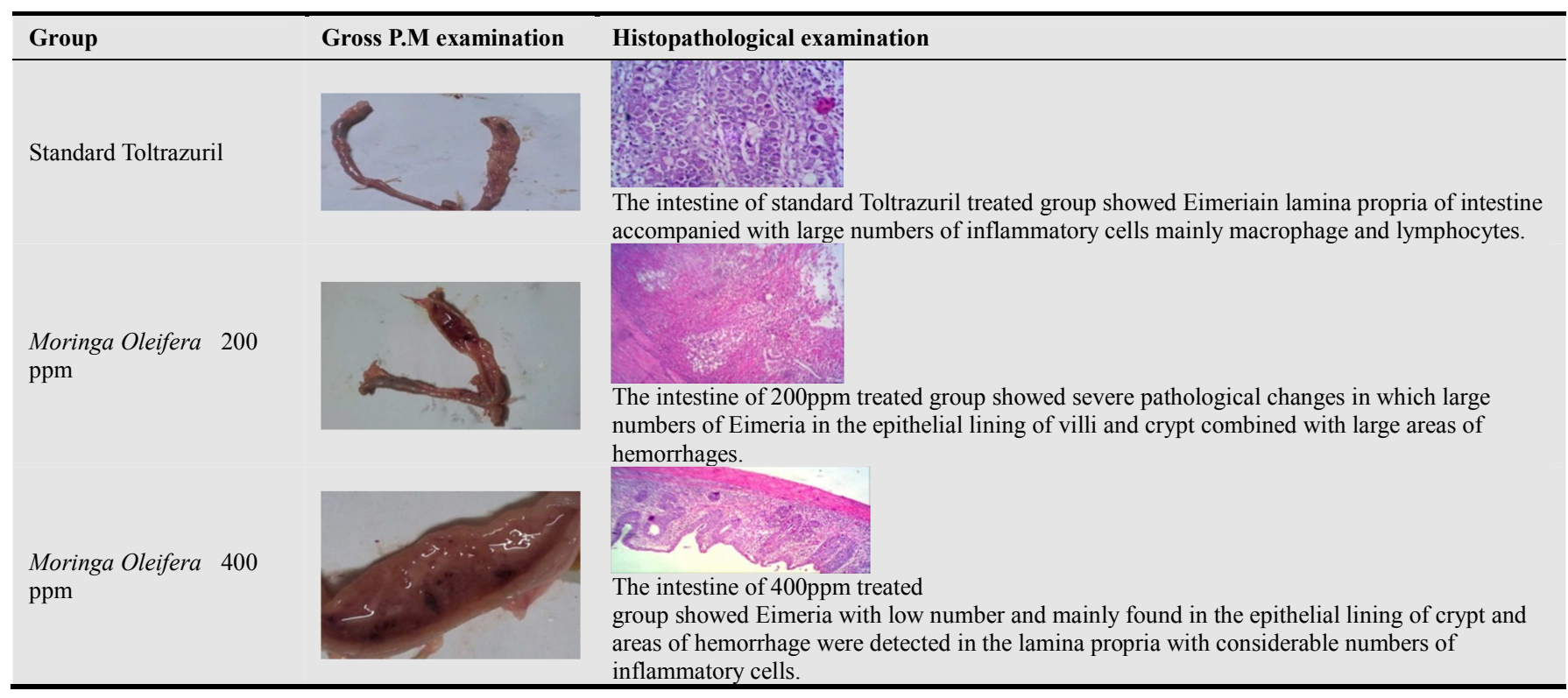

\section{Discussion}

The result of acute oral toxicity (LD50) study of ethanolic leaf extract of Moringa Oleifera showed no mortality at the maximum dose of $6000 \mathrm{mg} / \mathrm{kg} /$ body weight. In an acute oral toxicity study by [16], Moringa Oleifera leaf extract was documented to be non-lethal in animals at $6400 \mathrm{mg} / \mathrm{kg}$ body weight. In addition, [17] found that Moringa Oleifera leaf extract was documented to be non-lethal in animals at 2000 $\mathrm{mg} / \mathrm{kg}$ body weight. More so, the report of [18] revealed that the aqueous extract of Moringa Oleifera leaf is safe at dosage as high as $5000 \mathrm{mg} / \mathrm{kg}$. These results may indicate safety of ethanolic or aqueous leaf extract of Moringa Oleifera when administrated orally as the acute administration of $2 \mathrm{~g} / \mathrm{kg}$ dose was reported to be the ceiling point for acute oral toxicity of medicinal plants [19].

Eimeria is an intracellular parasite, must adhere to and invade the intestinal epithelial cells in order to replicate. Gut-adapted microorganisms may compete for adhesion and invasion of cells. In the present study and after challenging the chicks with mixed Eimeria especially in the control non treated group, birds showed severe form of coccidiosis represented by a high mortality rate $(26.7 \%)$, lesion score was 3.57 and fecal score was 4.8 (meaning severe watery diarrhea with obvious amount of voided blood in litter). Addition of 0.5 and $1 \%$ of $M$. Oleifera powdered leaves reduced mortality to be 6.7 and $3.3 \%$ respectively. In addition, Inclusion of $M$. Oleifera powder $(0.5$ and $1 \%)$ to broiler's feed were very efficacious and equal to diclazuril feed additive in preventing symptoms of coccidiosis associated with experimental infection with mixed Eimeria species. Birds supplemented with $M$. Oleifera $(0.5$ and $1 \%)$ and feed additive form of Diclazuril at a concentration of $1 \mathrm{ppm}$ showed a significant reduction in the cumulative mean oocysts shed $(67.8 \pm 4.52$, and $44.4 \pm 3.38 \& 36.7 \pm 5.62 \times 10^{3} / \mathrm{g}$, respectively) in comparison with the control non-treated birds (629. $75 \pm$ $23.47 \times 103 / \mathrm{g}$ ). Oral supplementation of bird infected with mixed Eimera species by powdered leaves of M. Oleifera $(0.5$ and $1 \%)$ showed significant decrease in lesion score $(0.72$ \pm 0.022 and $0.40 \pm 0.011$ respectively). These findings were similar or better than those obtained in group treated with standard anticoccidial drug.

Our finding is matched with our histopathological study where the intestine of broilers supplemted with either 0.5 or $1 \%$ appeared devoid from Eimeria and the lamina propria was infiltrated with inflammatory cells mainly macrophages and lymphocytes

Birds infected with mixed Eimera species and treated with ethanolic extract of M. Oleifera (200 and $400 \mathrm{mg} /$ liter for 5 consecutive days) in drinking water showed a significant anticoccidial activity indicated by decreasing the total ocyst count $(285.2 \pm 9.45$ and $146.6 \pm 8.57 \times 103 / \mathrm{g}$ respectively), decrease in lesion score $(1.1 \pm 0.12$ and $0.81 \pm 0.14$ respectively) compared with infected non treated group (Total oocyst of $621.8 \pm 17.38$ and lesion secore $=3.57 \pm 0.51)$ and those treated with reference drug ((Total oocyst of $256.75 \pm$ 21.43 and lesion score of $0.97 \pm 0.067)$. Concerning the fecal score records, the results of Moringa. treated groups were 1.9 \pm 0.44 and $1.5 \pm 0.31$ for 200 and $400 \mathrm{mg} /$ liter compared to $4.8 \pm 0.42$ for the control non- treated group and $1.4 \pm 0.23$ for the reference group treated with $25 \mathrm{ppm}$ toltrazuril for 2 consecutive days. The curative anticoccidial activity reported for M. Oleifera ethanolic extract in the present study is matched with our histopathological study where the intestine Moringa treated group showed presence of low number of Eimeria in the crypt and in the epithelial lining compared with the infected non-treated group and lamina propria was infiltrated by large numbers of inflammatory cells. Bloody colored diarrheal feces indicated by fecal score were seen in all groups following the onset of clinical signs in infected broiler chickens. The bloody diarrhea was milder in all the 
treatment (toltrazuril and ethanolic extract of $M$. Oleifera ) groups as the days progressed. This can be attributed to the reduction of oocyst shed in the feces of the broiler chickens as the day progressed. The reduction of oocyst shed in the feces will result in reduced damage caused on the intestinal lining and as a result the reduction in the level of hemorrhage. On the five day treatment of the present study, the feces of the birds treated with 200 or $400 \mathrm{mg} / \mathrm{kg}$ body weight of M. Oleifera were devoid of diarrhea blood (fecal score, $1.9 \pm 0.44$ and $1.5 \pm$ 0.31 respectively) compare to values of control non-treated group (4.8 \pm 0.42$)$.

The use of $M$. Oleifera is justified on the basis that it possesses anti-malaria properties [5] as well as anti-leishmanial activity [7] and Eimeria belongs to the phylum Apicomplexa as does the Plasmodium parasite. The result of the oocyst inhibition in the fecal matter shows that birds treated with powdered leaves of $M$. Oleifera at prophylactic study or ethanolic extracts at curative one were most promising with marked reduction of the total Eimeria oocyst shed in the feces. The anticoccidial activity of $M$. Oleifera either powdered leaves as prophylactic or ethanolic extract as treatment agents could be attributed to the antioxidant properties possessed by $M$. Oleifera. Antioxidant compounds are also well known to have a cellular protective action against oxidative stress and reduce the severity of E. tenella infections by altering the degree of intestinal lipid peroxidation[1]. The antioxidant properties of $M$. Oleifera have been reported previously by $[20,21]$ which are ascorbic acid, flavonoids, phenolics and carotenoid. In different physio-pathological conditions, the systemic amounts of free radicals and reactive oxygen species are higher than normal [22]. Free radical oxidative species are known to be produced during the host's cellular immune response to invasion by Eimeria species [23], which play an important role in defending mechanism against parasitic infections. However, their high concentrations may become intolerable to cell causing tissue damage and cytotoxicity and partially contributing to the pathology of infection. In some parasitic infections, decrease in the content of antioxidants like Vitamine A, C and $\mathrm{E}$ occur in the host cell [24]. Another free radical oxidative species, nitric oxide enhance vasodilation and hemorrhages in coccidial infections and could be toxic to both parasite as well as to host cells harboring the coccidian parasite [25]. In addition, [26, 27] reported that $E$. acervulina oocysts motivate the lipid peroxidation, increase oxidative damage and imbalance in the antioxidant status in the infected birds by disturbing the oxidative balance. Therefore, to alleviate or reduce the oxidative stress by inclusion of antioxidants as feed supplements either natural as Vitamin E\& Se or synthetic as butylated hydroxytoluene are commonly used in the poultry industry.

Inclusion of $M$. Oleifera either powder leaves ( 0.5 and $1 \%)$ to broiler's feed in prophylactic anticoccidial study or the ethanolic extract of $M$. Oleifera leaves $(200$ and $400 \mathrm{mg} / \mathrm{kg}$ b.wt.) in curative study had a good dose related response to the improvement of body weight gain in broiler chickens infected with mixed species of Eimeria. Our Findings showed that the infected non- treated group had $19.5 \%$ weight loss; this could be as a result of the damaging effect of the Eimeria species on the epithelial lining of the intestines which in turn impairs the absorption of nutrient and water from the intestine. The weight gain observed in the groups treated with $M$. Oleifera leaves could also be due to its nutritional value, having crude protein of $17.01 \%$, carbohydrate $(63.11 \%)$, crude fat $(2.11 \%)$ and energy (1440.11 kcal/100 g) according to [28]. However, $[29,30]$ reported that $M$. Oleifera leaf meal has 27.1 and $27.51 \%$ crude protein respectively. The improvement of the body weight could as well be attributed to the high levels of vitamins and amino acids in $M$. Oleifera leaves which improve recovery from the disease condition and increase feed intake and feed conversion rate.

\section{Conclusion}

The present study confirms that M. Oleifera possessed a marked anticoccidial activity and could be useful as alternative product for the control of avian coccidiosis in poultry production. It is possible of its use as prophylactic and curative agent for coccidia in addition to its growth promoting effect, safety as well as its antibacterial effect

\section{References}

[1] Allen, P. C., Danforth, H. D. \& Augustine, P. C. (1998): Dietary modulation of avian coccidiosis. Interenational Journal of Parasitology 28, 1131-1140.

[2] Chapman, H. D. (1997): "Biochemical, genetic and applied aspects of drug resistance in Eimeria parasites of the fowl," Avian Pathology 26, 221-244.

[3] Youn, H. J. and Noh, J. W. 2001. Screening of the anticoccidial effects of herb extracts against Eimeria tenella. Veterinary Parasitology 96, 257-263.

[4] Mishra, G.; Singh, P.; Verma, R.; Kumar, S.; Saurabh, S.; Jha, K \& Khosa, R. L.(2011): Traditional Uses, Phytochemistry and Pharmacological Properties of Moringa Oleifera plant: An Overview. Scholars Research Library. Der Pharmacia Lettre 3(2), 141-164.

[5] Farooq, A.; Sajid, L.; Muhammad, A. \& Anwarul-Hassan, G. (2007): Moringa Oleifera : a food plant with multiple medicinal uses. PhytotherRes, 21, 17-25.

[6] Ola-Fadunsin, S. D. \& Ademola, I. O. (2013): Direct effects of Moringa Oleifera Lam (Moringaceae) acetone leaf extract on broiler chickens naturally infected with Eimeria species. Trop Anim Health Prod.

[7] Singh M K, Paul J, De T, Chakraborti T. (2015): Bioactivity guided fractionation of Moringa Oleifera Lam. flower targeting Leishmania donovani. Indian J Exp Biol.; 53(11): 747-52.

[8] Handa, S. S. (2008): An Overview of Extraction Techniques for Medicinal and Aromatic Plants. In Handa, S. S.; Khanuja, S. P. S.; Longo, G. \& Rakesh, D. V., Extraction Technologies for Medicinal and Aromatic Plants, p.p 26. International Centre for Science and High Technology, Italy. 
[9] -Kerber, G. (1941): Pharmakologische Methoden Zur Auffindung Von Arzneimitten und Gifter und Analyse ihrer Wirkungsweise Vor. Dr. Med. Leopold Ther.Wissenschaftliche verlage Gerlarge Gesse Gesellschaft. M. B. H.

[10] Long, P. L. (1971): Maintenance of intestinal protozoa in-vivo with particular reference to Eimeria and Histomonas. In Isolation and Maintenance of Parasites in-vivo, 9thSymposium of the British Society for Parasitology, 65-75. Oxford: Blackwell.

[11] Norton, C. C., and L. P. Joyner (1968): The freeze preservation of coccidia. Res Vet Sci 9:598-600.

[12] Long, P. L.; Joyner, L. P. \& Millard, B. J. (1976): A guide to laboratory techniques used in the study and diagnosis of Av.coccidisis. Folia Vet. Lat., (6), 201-217.

[13] Davis, L. R. (1973): Techniques. In The Coccidia, ed. D. M. Hammond and P. L. Long, 411-58. Baltimore, MD: Univ. Park Press.

[14] Johnson, J. E. \& Reid, W. M. (1970): Anticoccidial drugs: Lesion scoring technique in battery and floor pen experiment with chickens. Exprel.Parasitol., 28,30-36.

[15] Hodgson, J. N. (1970): Coccidiosis: Oocysts counting technique for coccidiostat evaluation. Exprel.parasitol, 28, 99-102.

[16] Awodele, O.; Oreagba, I. A.; Odoma, S.; da Silva, J. A. \& Osunkalu, V. O. (2012): Toxicological evaluation of the aqueous leaf extract of Moringa Oleifera Lam. (Moringaceae). J Ethnopharmacol, 139(2), 330-336.

[17] Adedapo, A. A.; Mogbojuri, O. M.; Emikpe, B. O. (2009): Safety evaluations of the aqueous extract of the leaves of Moringa Oleifera in rats. J Med. Plants Res., 3, 586-591.

[18] Diallo, A.; Eklu-Gadegkeku, K.; Mobio, T.; Moukha, S. \& Agbonon, A.; (2009): Protective effect of Moringa Oleifera Lam. and Lannea kerstingii extracts against cadmium and ethanol-induced lipid peroxidation. $J$ Pharmacology and Toxicology, 4, 160-166.

[19] 1Lu, F. C.; Jessup, D. C. and Lavallée, A. (1965): Toxicity of pesticides in young versus adult rats. Food Cosmet. Toxicol., 3, 591-596.
[20] Siddhuraju, P. \& Becker, K. (2003): Antioxidant properities of various solvent extracts of total phenolic constituents from three different agroclimatic origins of drumstick tree $(M$. Oleifera Lam.) Leaves. J agric. food chem., 51, 2144-2155.

[21] Dillard, C. J. \& German, J. B. (2000): Phytochemicals: nutraceuticals and human health: A review. J Sci., Food Agric., $80,1744-1756$.

[22] Vladimirov YA, (2004); Reactive oxygen and nitrogen species diagnostic, preventive and therapeutic values. Biochemistry (Moscow), 69: 1-3.

[23] Allen PC, J Lydon and HD Danforth, (1997): Effects of components of Artemisia annua on coccidian infections in chickens. Poult Sci, 76: 1156-1163.

[24] Evans P and B Halliwell, (2001): Micronutrients: oxidant/antioxidantstatus. J Nut, 121: 324-338.

[25] Ovington KS and NC Smith, (1992): Cytokines, free radicals and resistance to Eimeria. Parasitol. Today, 8: 422-426.

[26] Georgieva NV, M Gabrashanska, V Koinarski and Z Yaneva, (2011). Zinc supplementation against Eimeria acervulina-induced oxidative damage in broiler chickens. Vet Med Int, http://dx.doi.org/10.4061/2011/647124

[27] Georgieva NV, M Gabrashanska and V Koinarski, (2011): Ermidou-Pollet S Antioxidant status in Eimeria acervulina infected chickens after dietary selenium treatment. Trace Elem Elec, 28: 42-48.

[28] Ogbe, A. O. \& John P. A. (2012): Effect of Polyherbal Aqueous Extracts (Moringa Oleifera, Gum arabic and wild Ganoderma lucidum) in Comparison with Antibiotic on Growth Performance and Haematological Parameters of Broiler Chickens. Res. J. Recent Sci., 1(7), 10-18.

[29] Booth, F. E. M. \& Wickens, G. E. (1988): Non-timber uses of selected arid zone trees and shrubs in Africa. FAO conservation guide, Rome, pp 92-101.

[30] Oduro, I.; Ellis, W. O. \& Owusu, D. (2008): Nutritional potential of two leafy vegetables: Moringa Oleifera and Impomea batatas leaves. Science Research Essay, 3(2), 57-60. 